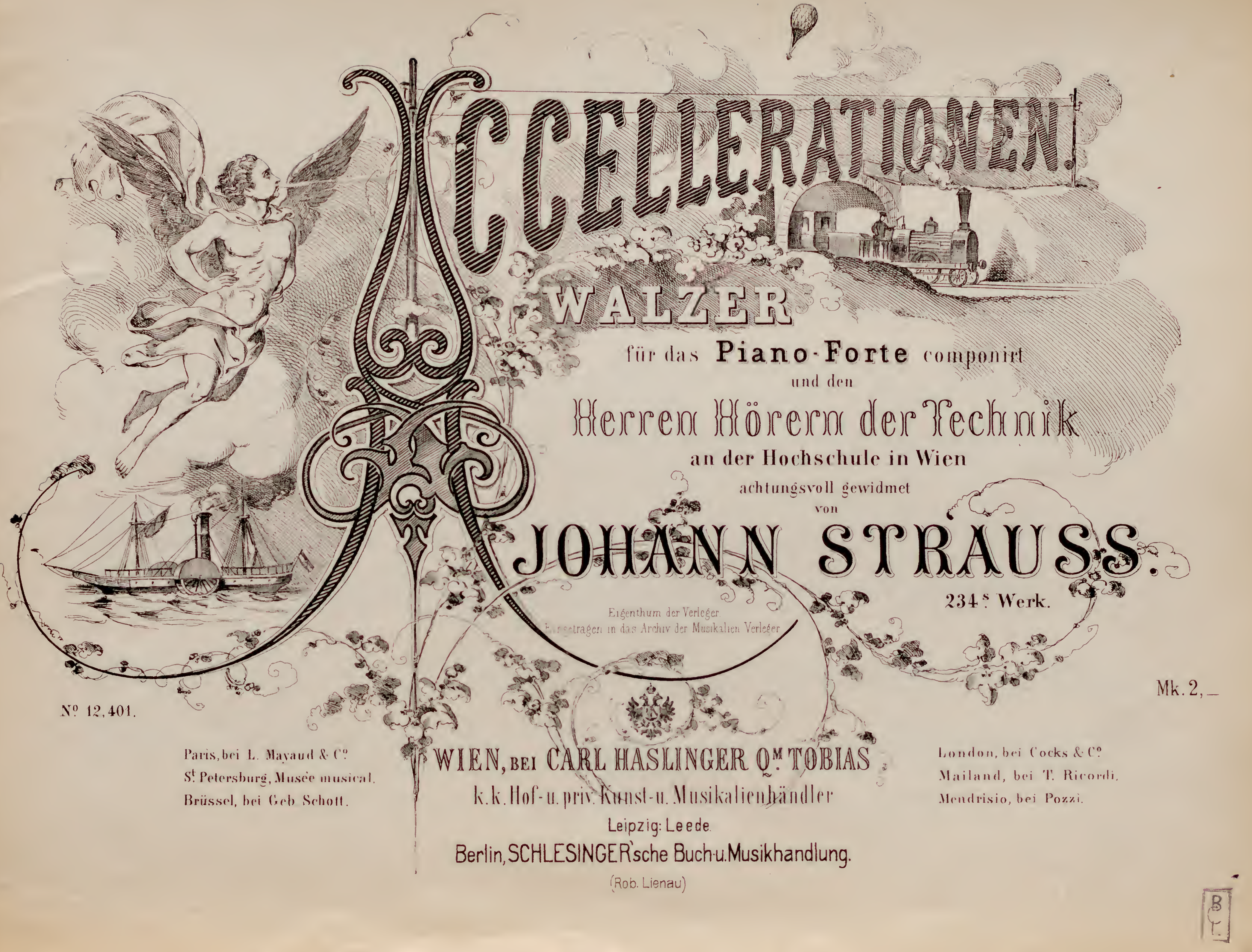


ICCELLERATIONEN.

\section{Johann Strauss.}

234: Werk.
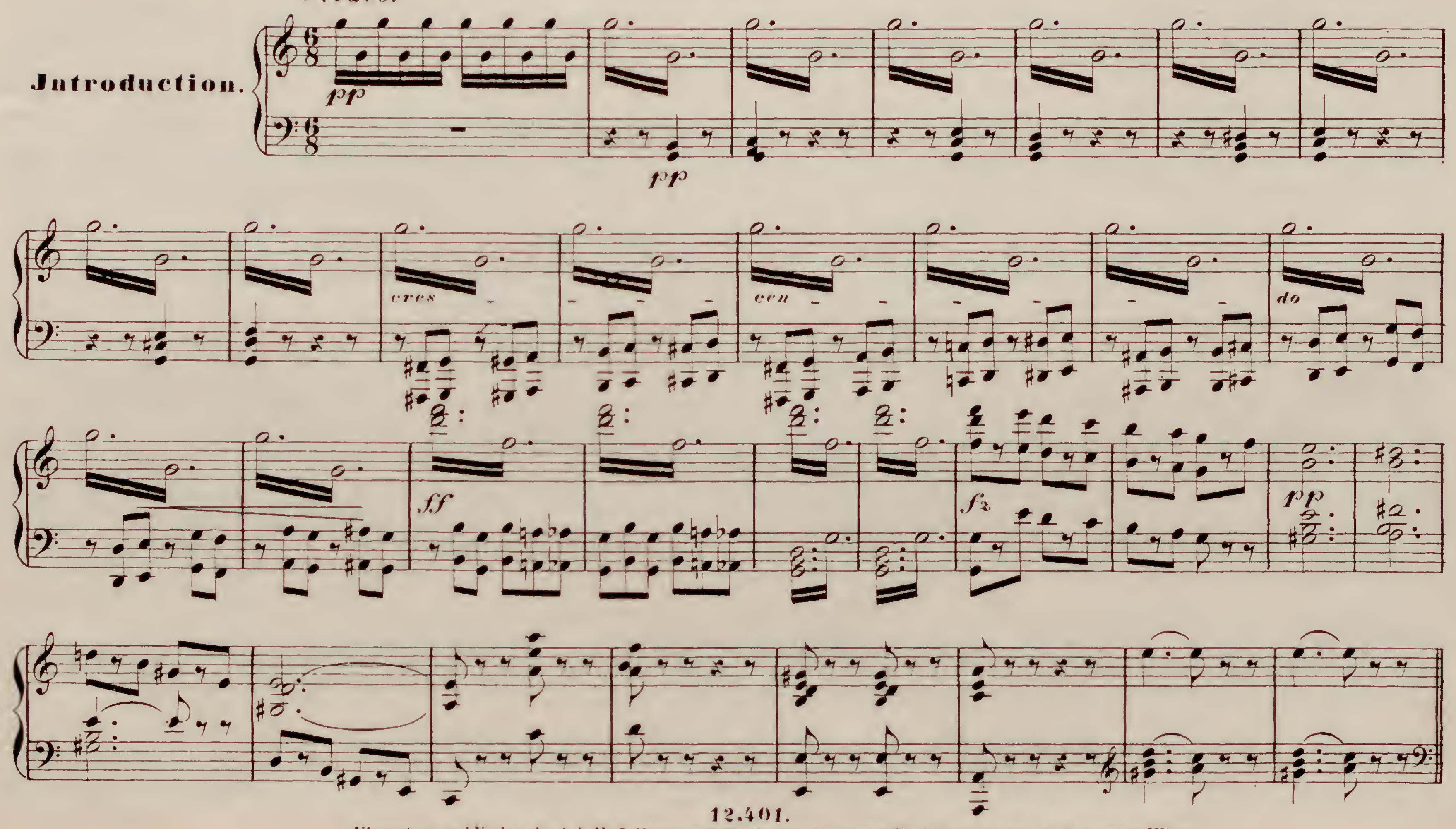

Kigenthum und Verlag der k.k. Hof L Lumet nund Mnsikalieuhandlung Carl Haslinger qm Tohias in Wien. 

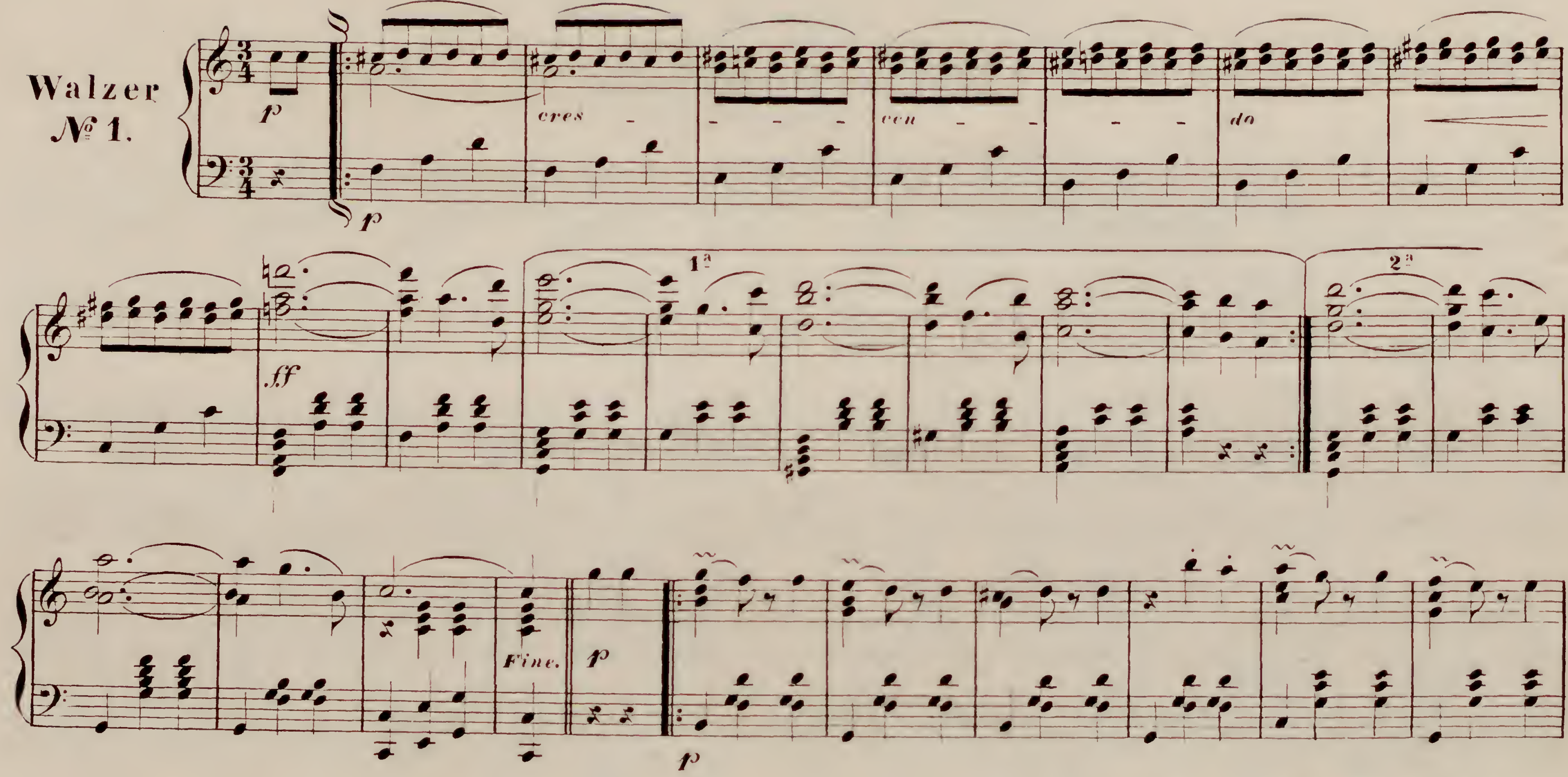

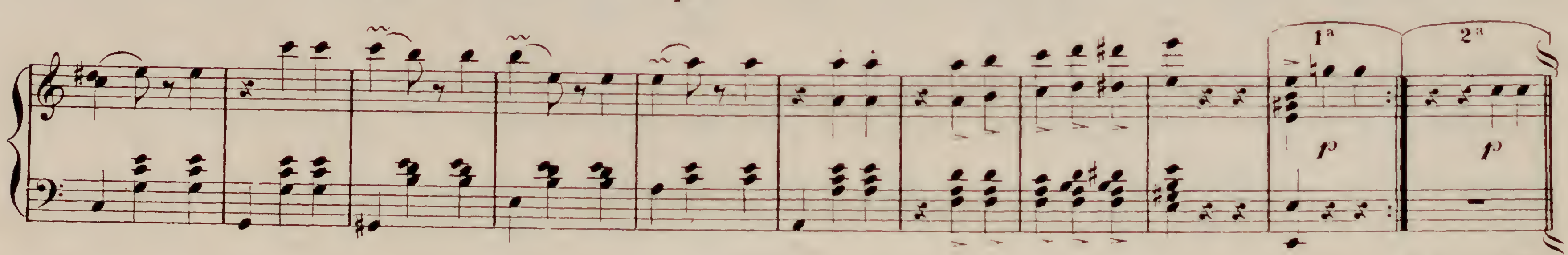
C.11. 12.4111. 


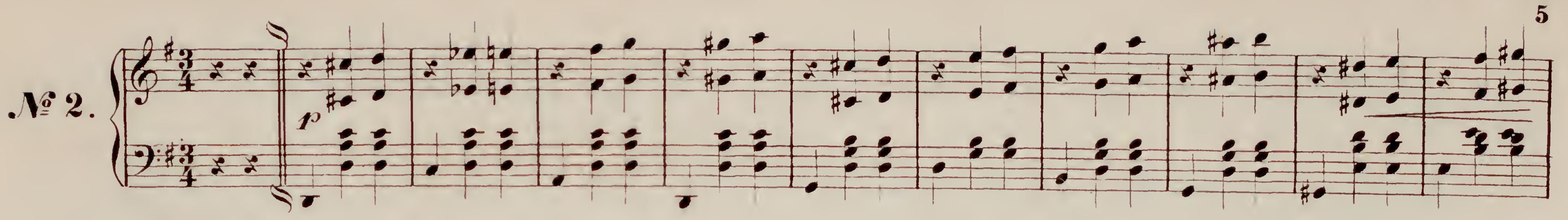

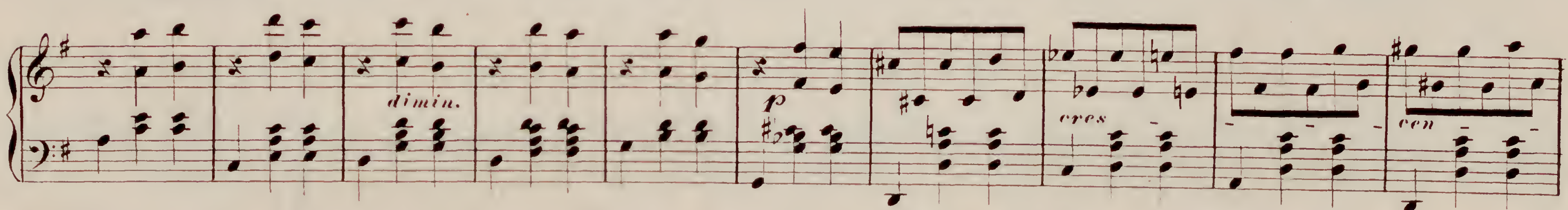

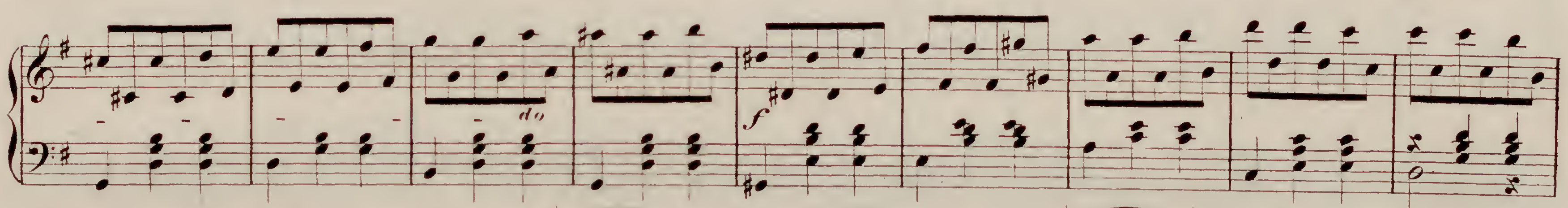

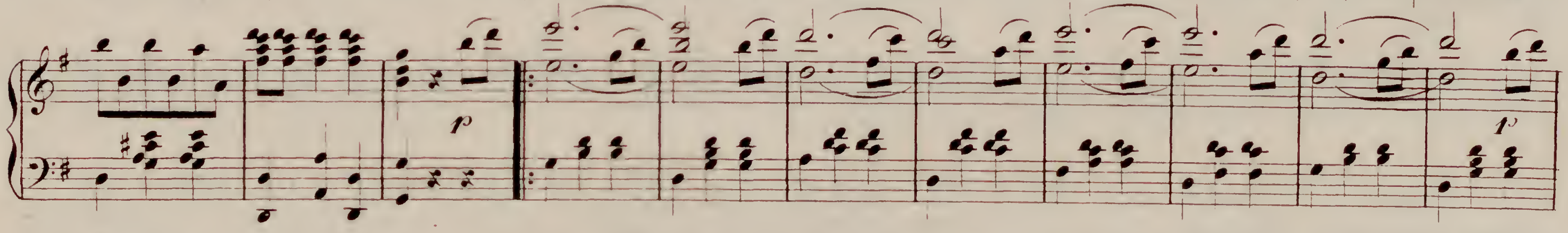

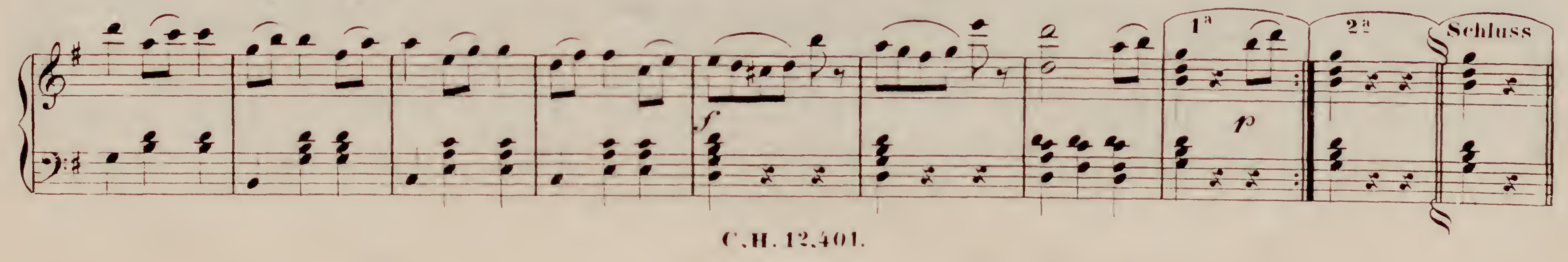


i)

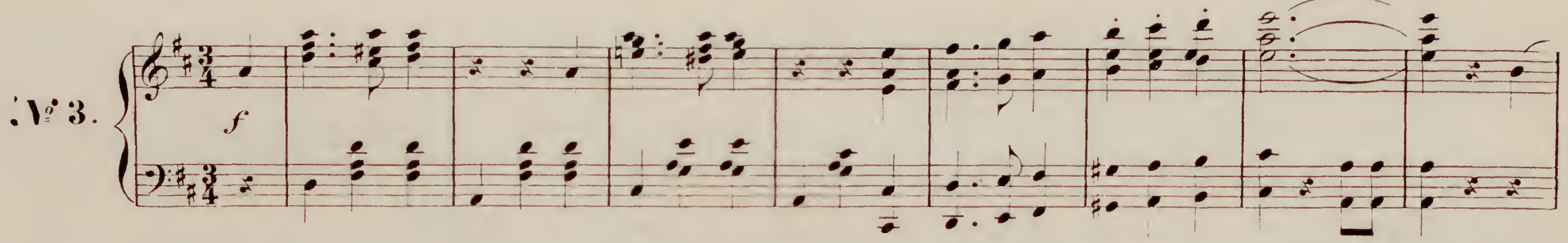

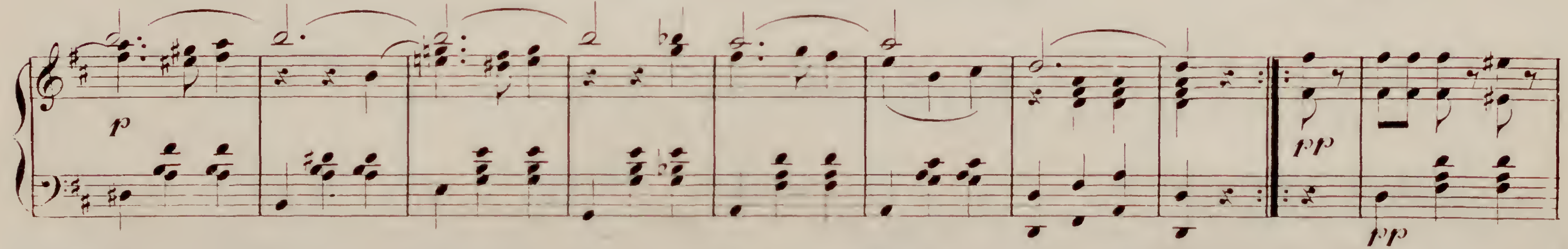

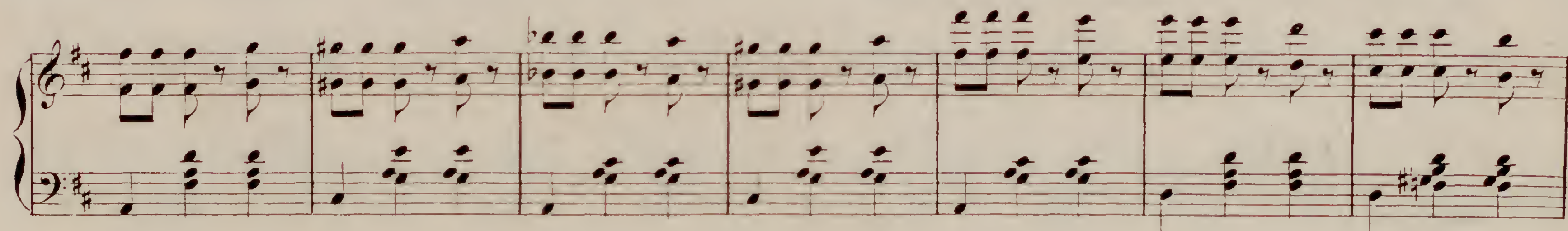

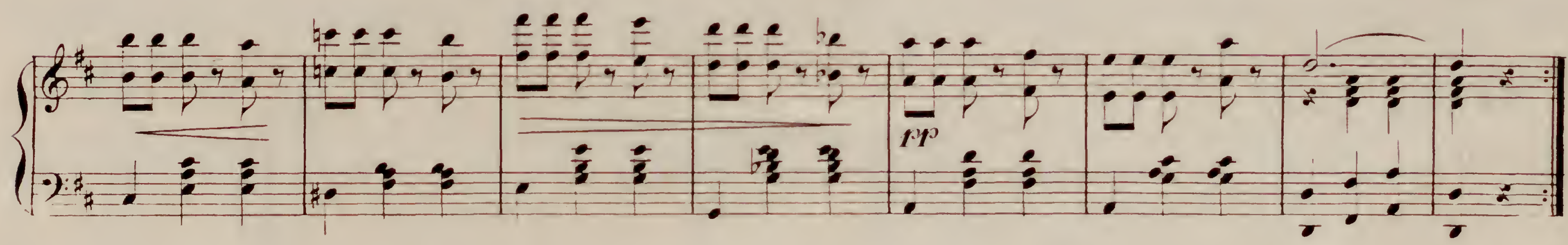
(.11.12.401 


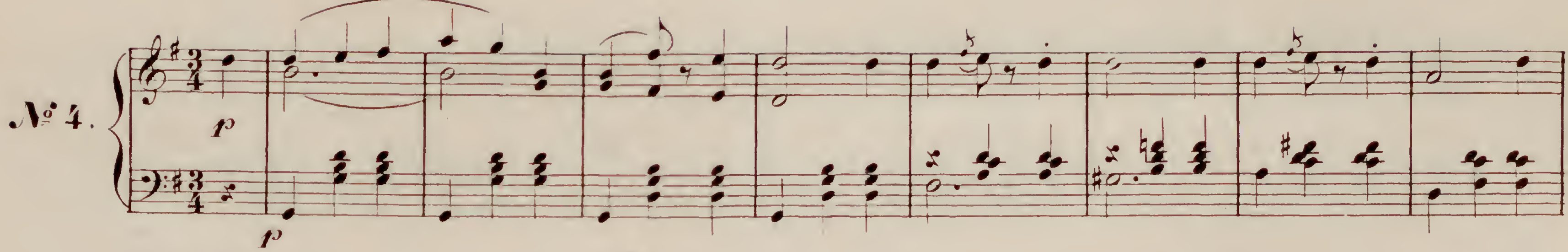
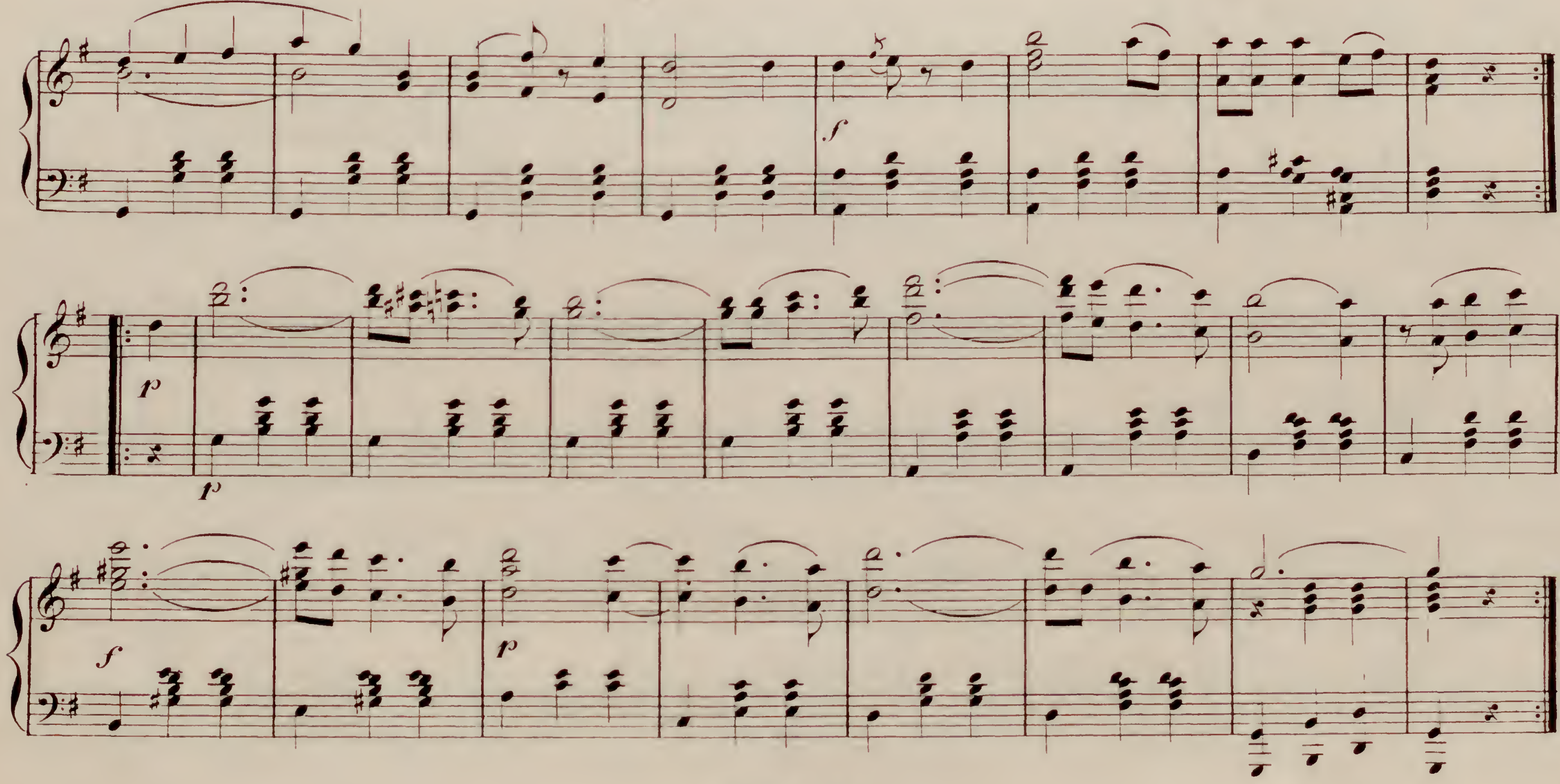

( . 1 . 1?.4111 
$x$

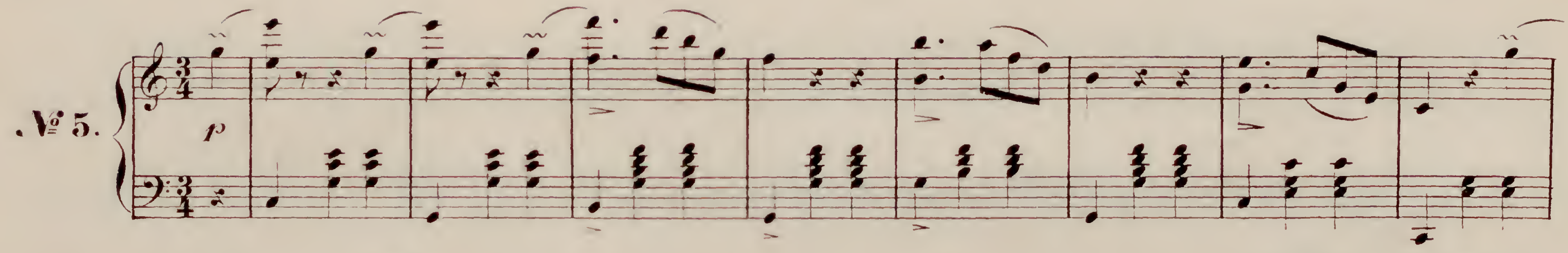

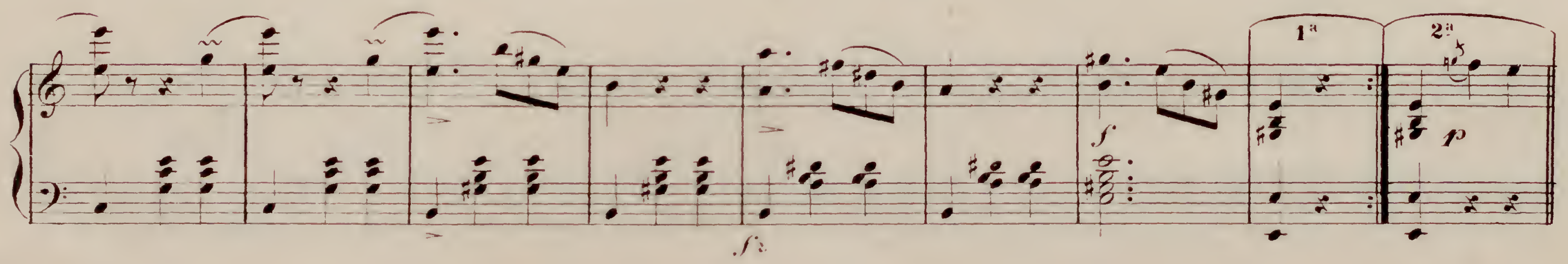

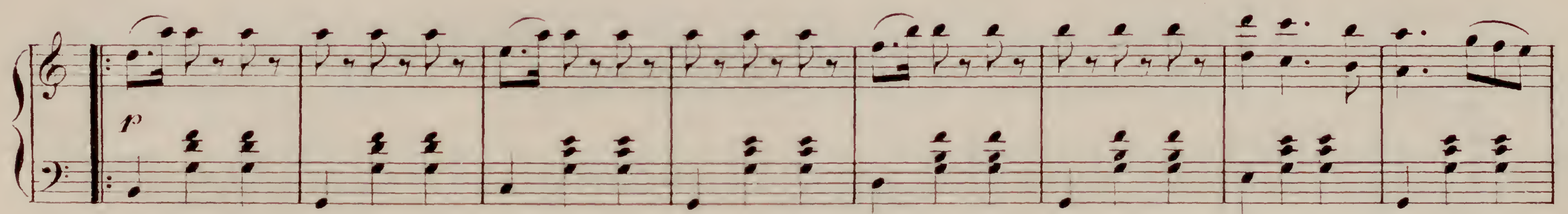

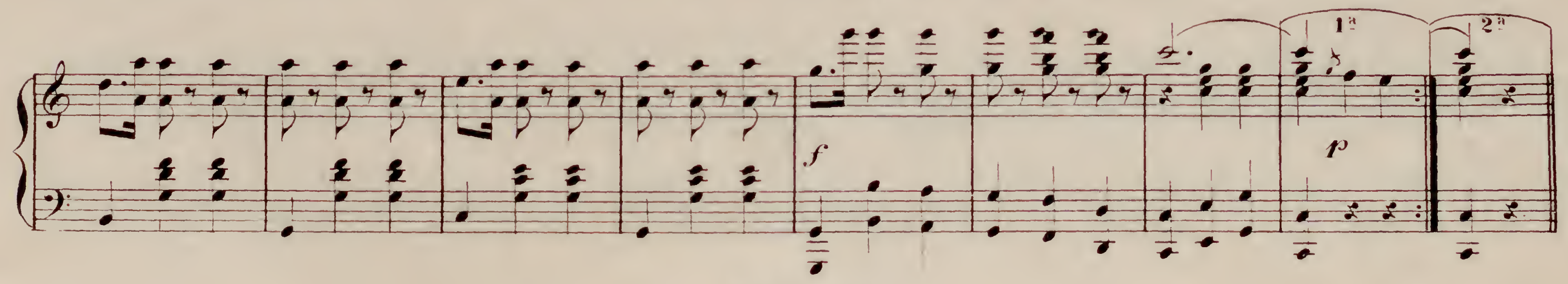
(.11. 12.4111. 


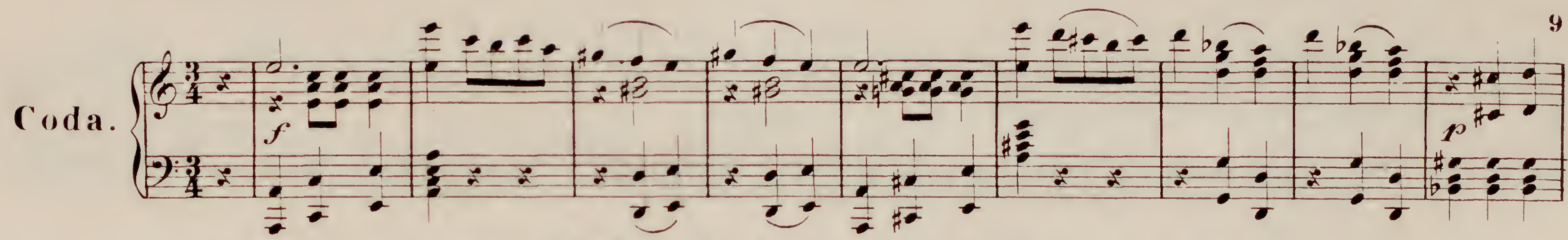

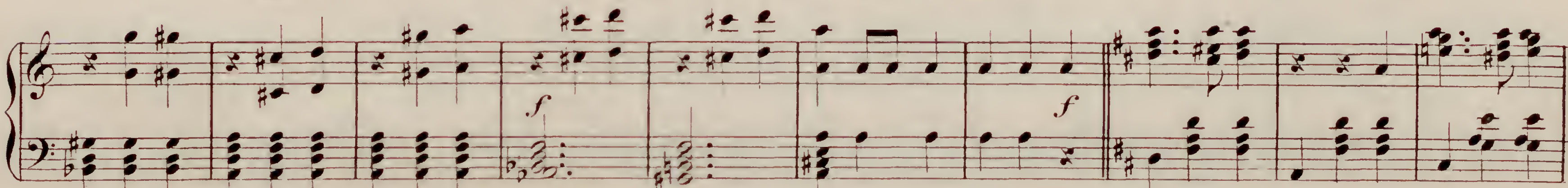

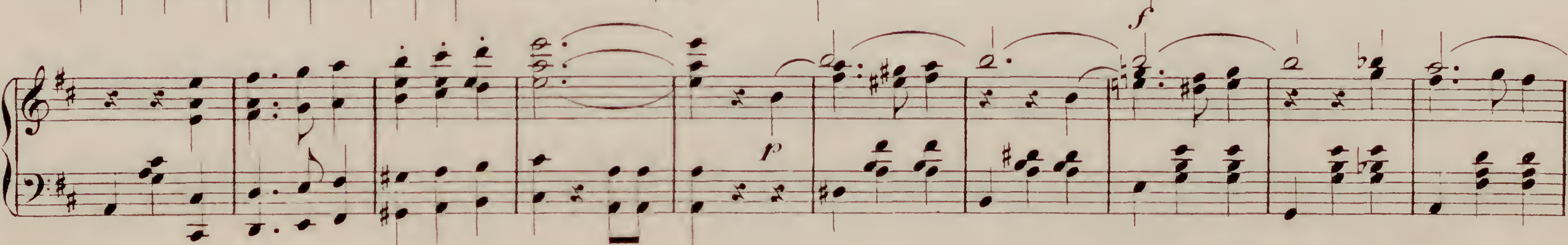

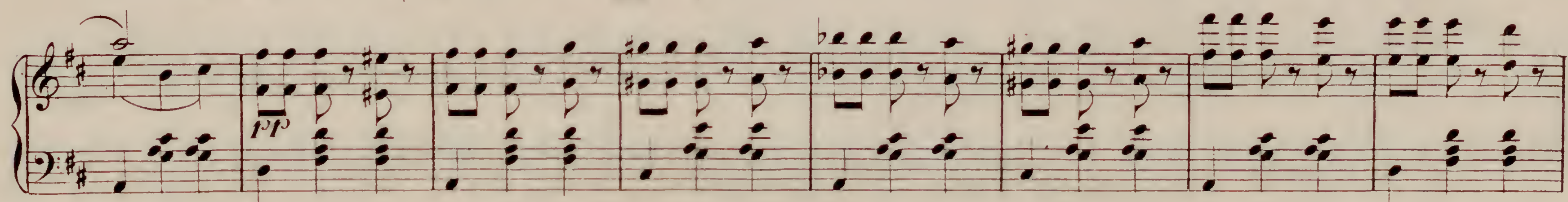

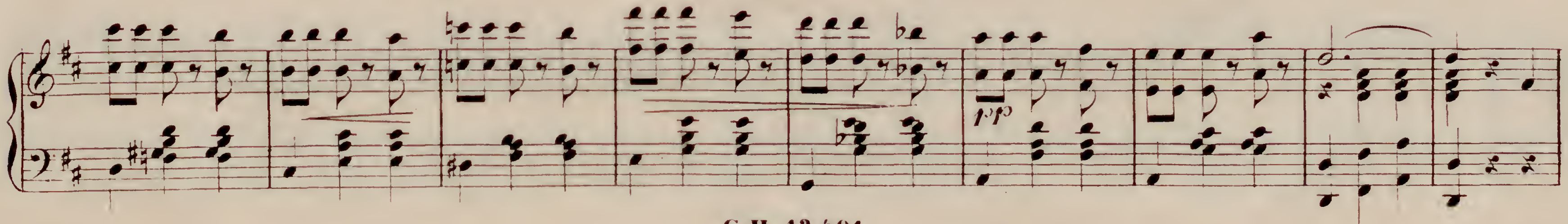
C.H. 12.401 


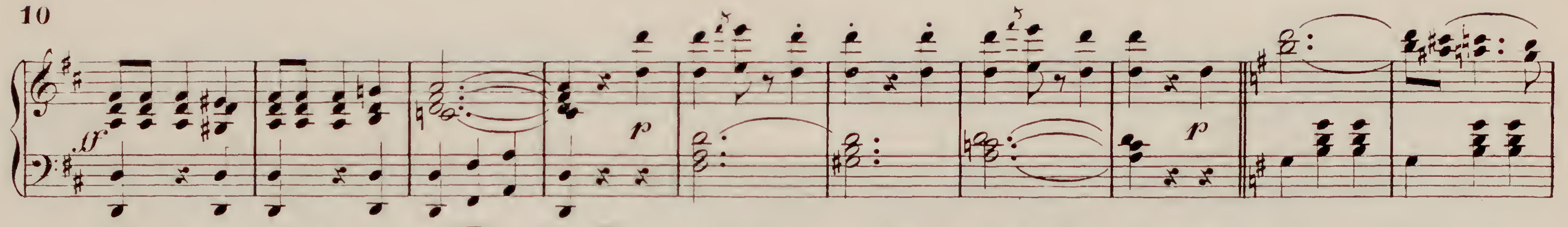

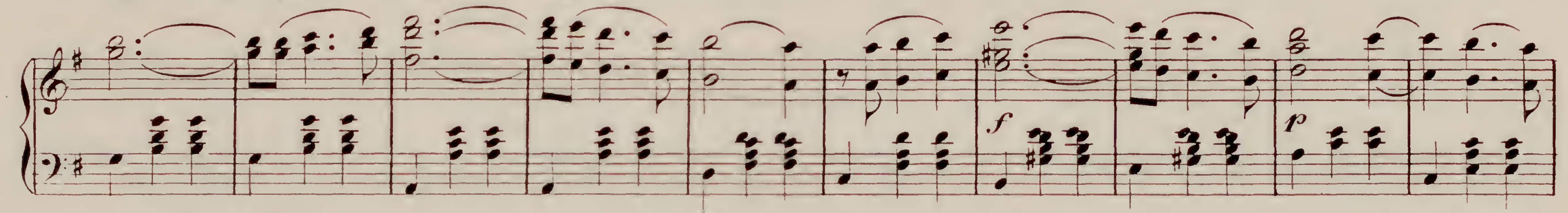

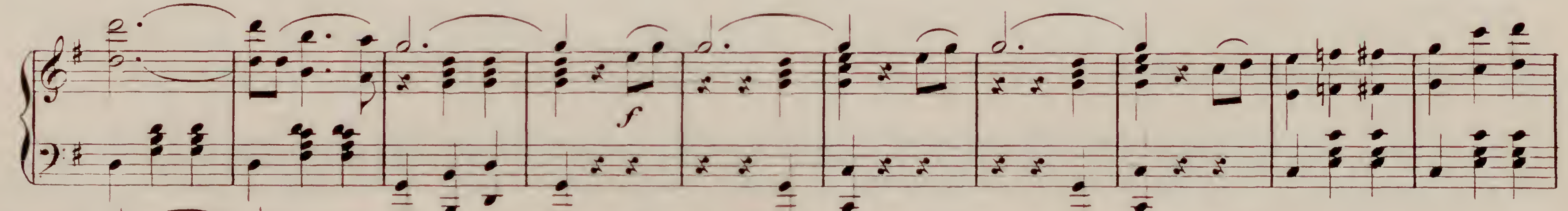

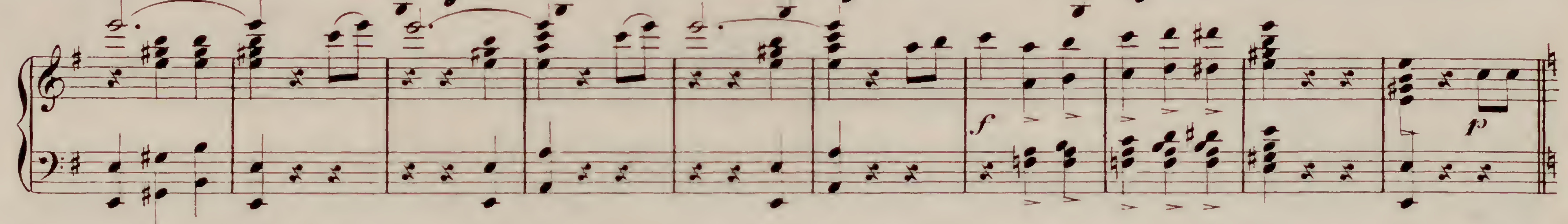

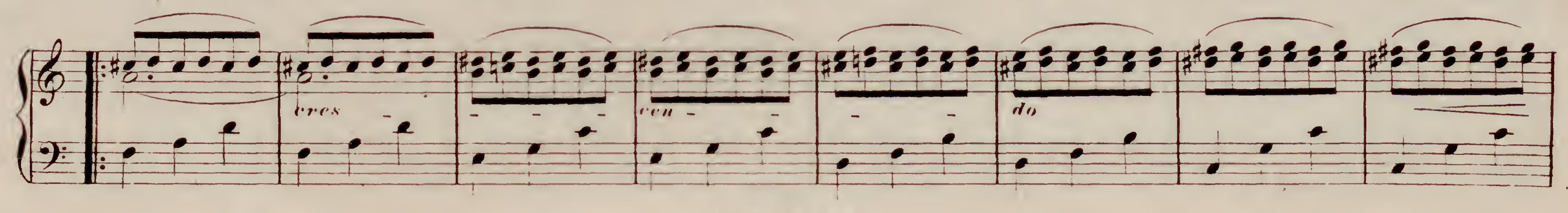



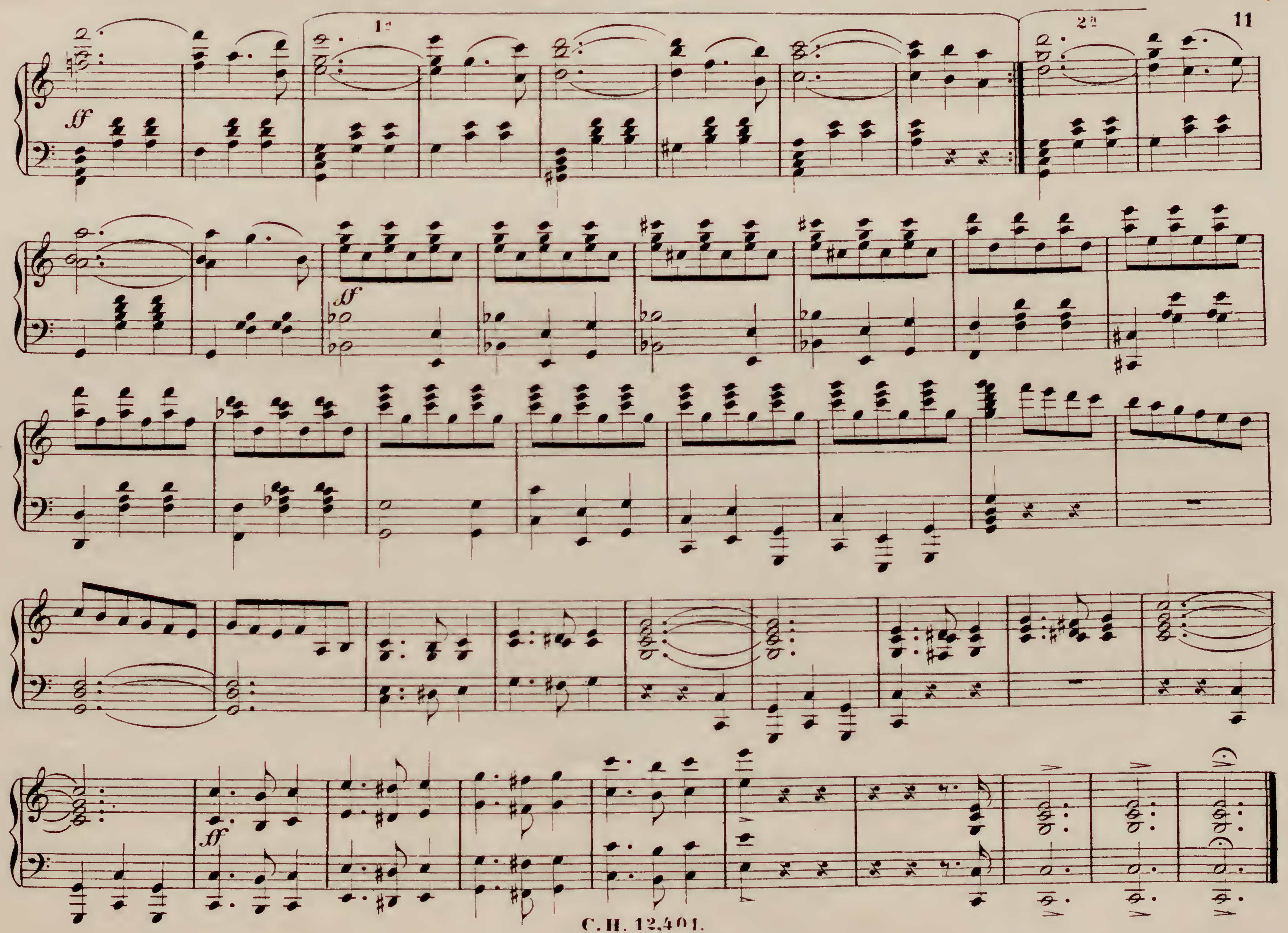
